Gut, 1989, 30, 1201-1205

\title{
Preference for hot drinks is associated with peptic disease
}

\author{
R C PEARSON AND R F MCCLOY \\ From the University Department of Surgery, Manchester Royal Infirmary, Manchester
}

SUmmary The temperature at which people chose to take a hot drink was measured in 59 patients with endoscopically proven peptic disorders of the upper gastrointestinal tract and 65 asymptomatic controls. The patients in the disease group drank significantly hotter tea or coffee than the control group (medians $62^{\circ}$ and $56^{\circ}$ Celsius respectively, $P<0 \cdot 0001$ ). The median temperatures of choice for subgroups of patients with oesophageal, gastric or duodenal disease were significantly higher than the control group $\left(63 \cdot 5^{\circ}, 63^{\circ}, 60 \cdot 5^{\circ} \mathrm{C}\right.$ respectively). There was no relationship between a preference for hotter drinks with either the sex or smoking habits of the patient. In the control group the temperature of choice tended to decrease with age though linear regression just failed to reach statistical significance $(p=0 \cdot 06)$; this trend was not apparent in the disease group $(p=0 \cdot 64)$. Thermal injury as a result of drinking hot fluids may be a causative factor in some peptic disorders.

An association between eating and drinking at high temperatures and disorders of the upper gastrointestinal tract has been taught to medical students for many years. T Lauder Brunton' and Ewald' related a preference for hot food and drink to gastric catarrh and ulcers, and this was reiterated at the beginning of this century by Heiser ${ }^{3}$ who reported that the majority of his ulcer patients preferred hot drinks. Logan Turner $^{4.5}$ and Watson ${ }^{6}$ both considered that the practice of drinking hot tea was a major aetiological factor for carcinoma of the oesophagus. Aetiological studies of both oesophageal cancer ${ }^{7-4}$ and gastric cancer, " " however, are inconclusive and contradictory.

Studies into the temperature of choice for hot drinks by Hunt ${ }^{12}$ and Edwards and Edwards ${ }^{13}$ reported high temperatures of ingestion, similar in each sex. In Edwards and Edwards study there was a correlation between a preference for hot drinks and severity of histologically graded gastritis. Davis and Ivy ${ }^{14}$, whilst confirming the high temperature of ingestion by many people, did not feel that the temperature transmitted to the upper gastrointestinal tract would be at an injurious level.

Address for correspondence: Mr R C Pearson. FRCS. University Department of Surgery. Manchester Royal Infirmary, Oxford Road, Manchester M1.3 9WL.

Accepted for publication 24 January 1989.
There is no reported work which ascertains whether or not there is a difference in the temperature of dietary intake between normal subjects and patients suffering from peptic disorders, excluding cancer. In this study the usual temperature at which hot drinks were consumed was measured in patients with peptic diseases and in asymptomatic volunteers.

\section{Methods}

SUBJECTS

Two groups of subjects were studied. Group A consisted of 65 volunteers taken from staff and patients all of whom were asymptomatic with regard to the upper gastrointestinal system. Of these nine had undergone upper gastrointestinal endoscopy which was normal in each case. None had a past history of dyspeptic symptoms. Group B consisted of 59 patients with known disease of the oesophagus, stomach, or duodenum. All had undergone upper gastrointestinal endoscopy within the previous month and all were symptomatic although the state of their disease - that is, active or inactive, was not ascertained immediately before testing. A standard proforma was completed for each subject before each test. If the patient had undergone endoscopy on the same day, testing was not carried out until at least two hours after the completion of the endoscopy. If the 
subject had also received intravenous sedation at the time of endoscopy, testing was performed at least 24 hours later. Each subject was provided with a standard sized $(240 \mathrm{ml})$ hospital cup of tea or coffee made to their usual taste. The temperature of the drink in the cup was continuously measured using a rapid response electronic thermometer (Model SM5), Scientific and Medical Products Limited, Manchester, UK). Tests were carried out in an open manner and subjects were asked to drink their tea or coffee normally; to facilitate this the test was carried out in a non-clinical, conversational ambience. Smokers were permitted to do so if they wished. As the drink was consumed the temperature in the cup was monitored. A chart was filled in noting the temperatures at which the drink was 'too hot', 'just right' and 'too cold'. At the same time the volume drunk at each phase was noted. The temperature when the drink was said to be 'just right' was called the upper limit, that when the drink was becoming 'too cold' was called the lower limit. The midpoint of the range when each subject chose to drink their tea or coffee has been called the preferred temperature and used as the data point for that subject. If the drink was finished before it became too cold, the temperature of the last mouthful was taken as the lower limit.

The two groups were similar with respect to age and sex; 38 of the 65 controls and 37 of the 59 disease subjects were men (not significant). The median ages were 47 years in the control group (range 20-92) and 49 years in the disease group (range 22-78), $(\mathrm{p}=0 \cdot 8)$. There were significantly more smokers in the disease group than in controls. As the preferred temperatures for each group were not normally distributed, the Mann Whitney U test (two tailed) has been used for comparative analysis.

\section{Results}

The range of temperature between the upper and lower limits of choice for each subject was the period when the middle two thirds of the drink was consumed. The median preferred temperature of the disease group $\left(62^{\circ} \mathrm{C}\right.$ range $\left.53^{\circ}-73^{\circ} \mathrm{C}\right)$ was significantly higher than that for the control group $\left(56^{\circ} \mathrm{C}\right.$ range $47.5^{\circ}-65^{\circ} \mathrm{C} p<0 \cdot 0001$ ), (Figure). This significance is maintained when the disease group is divided into patients with oesophageal disease, with gastric disease and with duodenal disease, and patients with mixed disease, and each compared with the control group (Table 1). Analysis of the disease group data excludes the possibility of endoscopy influencing the temperature test; there was no difference in preferred temperature within the disease group between those who had undergone gastroscopy within the previous

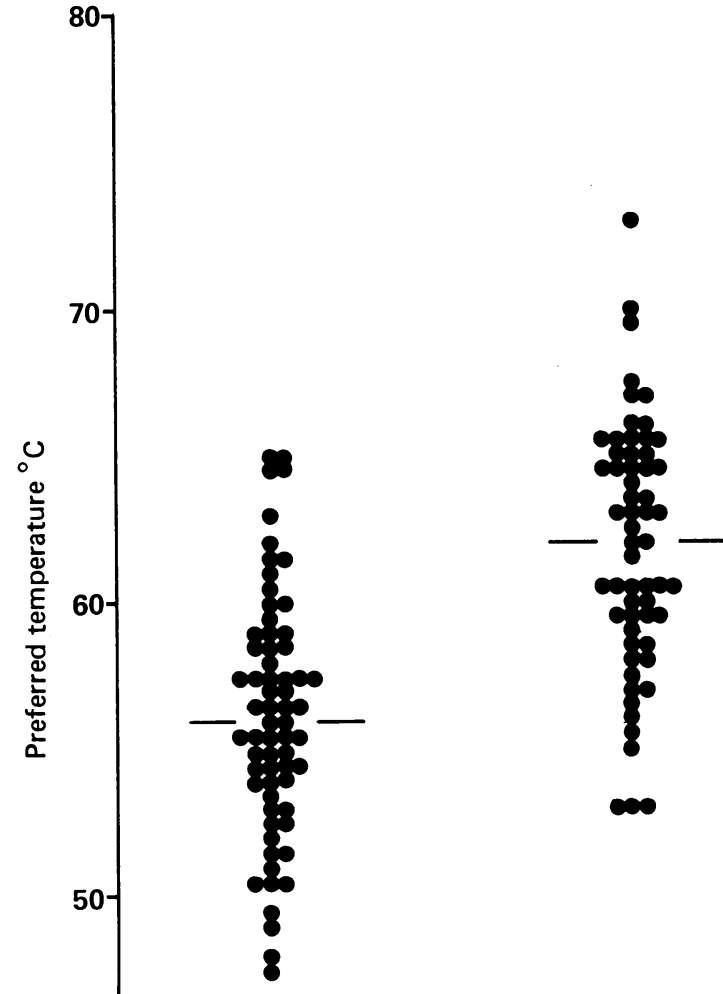

Controls

Disease

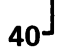

Figure Median preferred temperatures of ingestion for control subjects and patients with peptic disease; group medians (marked by har), controls $56^{\circ} \mathrm{C}$, range $47.5^{\circ}-65^{\circ} \mathrm{C}$, disease $62^{\circ} \mathrm{C}$, range $53-73^{\circ} \mathrm{C}, p<0 \cdot 0001$ Mann Whitney Utest.

24 hours, $\left(\mathrm{n}=20\right.$, median $62 \cdot 5^{\circ} \mathrm{C}$, range $\left.53^{\circ}-69 \cdot 5^{\circ} \mathrm{C}\right)$, and those who had not $\left(\mathrm{n}=39\right.$, median $62^{\circ} \mathrm{C}$, range $53^{\circ}-73^{\circ} \mathrm{C}$ ). The range of 'just right' temperature for each subject varied from $1^{\circ}-16^{\circ} \mathrm{C}$ (medians: control group $6^{\circ} \mathrm{C}$, disease group $7^{\circ} \mathrm{C}$ ). Linear regression (Spearman rho two tail) of range against median preferred temperature for all subjects and for subjects in each group suggests that at higher temperatures temperature differentiation is less accurate, range increasing at higher preferred temperatures $(\mathrm{p}<0 \cdot 001)$.

To determine whether smoking or sex exerted an effect on the preferred temperature, the data was divided into non-smokers and smokers, men and women, without regard to the presence or absence of 
Table 1 Preferred temperatures of ingestion in controls and peptic disease groups

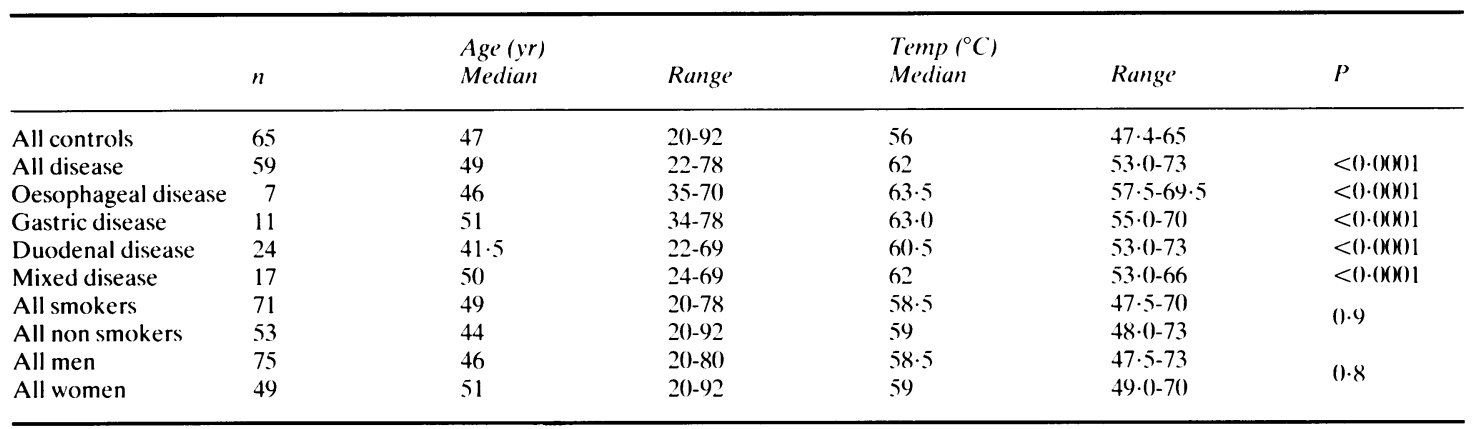

disease. There were 71 smokers from the two groups, and 53 non-smokers. There was no significant difference in age or preferred temperature between the two groups $(p=0.5$ and $p=0.9$ respectively). There were 75 men and 49 women. The median age of the women was slightly higher than men $(p=0.09)$ but no difference in median preferred temperature $(p=0.8)$ was apparent (Table 1). There was no significant difference in the numbers of male and female smokers.

The difference in preferred temperature between smokers in the control group and smokers in the disease group was highly statistically significant (Table 2). This difference was also apparent between non-smokers in the two groups. Non-smokers in the disease group, but not in the control group preferred their drinks at higher temperatures than the smokers in that group $\left(65^{\circ}\right.$ and $60.5^{\circ} \mathrm{C}$ respectively, $\left.\mathrm{p}<0.01\right)$. Similarly, for groups including any patient with oesophageal disease, gastric disease or duodenal disease, non-smokers had a significantly higher median preferred temperature than the smokers within that group. There were more smokers, how-

Table 2 Preferred temperatures of ingestion in smokers and non-smokers

\begin{tabular}{|c|c|c|c|c|c|}
\hline \multirow[b]{3}{*}{ Controls } & \multicolumn{4}{|c|}{ Median preferred temperature $\left({ }^{\circ} \mathrm{C}\right)$} & \multirow{3}{*}{$\frac{p(\text { two tail })}{0.18}$} \\
\hline & \multirow{2}{*}{$\begin{array}{l}\text { Smokers } \\
55.5\end{array}$} & \multirow{2}{*}{$\begin{array}{l}n \\
29\end{array}$} & \multicolumn{2}{|c|}{ Non-smokers $n$} & \\
\hline & & & $56 \cdot 5$ & 36 & \\
\hline Disease & $60 \cdot 5$ & 42 & $65 \cdot()$ & 17 & $0 \cdot 01$ \\
\hline Controls & $55 \cdot 5$ & 29 & & & \\
\hline Disease & $60 \cdot 5$ & 42 & & & $<0 \cdot(0) 01$ \\
\hline Controls & & & $56 \cdot 5$ & 36 & $<0.0 \times 001$ \\
\hline Disease & & & $6.5 \cdot()$ & 17 & $<0 \cdot(\pi) 1$ \\
\hline \multicolumn{6}{|l|}{ Oesophageal } \\
\hline disease & $61 \cdot 5$ & 10 & 6.5 & 5 & $<0 \cdot() 2$ \\
\hline Gastric disease & 60.5 & 20 & 65 & 4 & $<0 \cdot(02$ \\
\hline \multicolumn{6}{|l|}{ Duodenal } \\
\hline disease & $60 \cdot 5$ & 26 & $64 \cdot 5$ & 13 & $<0 \cdot() 2$ \\
\hline
\end{tabular}

ever, than non-smokers in each group and the numbers with this further subdivision, particularly of non-smokers are smaller. The preferred temperature appeared to decrease slightly with age in the control group, though linear regression failed to reach statistical significance $(r=0.213, p=0.06)$. This trend was lost in the disease group $(r=0 \cdot 061, p=0 \cdot 64)$.

There was no difference in preferred temperature between all patients drinking tea $(n=64)$ and all those drinking coffee $(\mathrm{n}=60)$, medians $59^{\circ} \mathrm{C}\left(48^{\circ}-73^{\circ}\right)$ and $58.5^{\circ} \mathrm{C}\left(47 \cdot 5^{\circ}-69 \cdot 5^{\circ}\right), \mathrm{p}=0 \cdot 6$. More patients in the disease group chose to drink tea $(n=38)$ and more in the control group took coffee $(n=39)(p=0 \cdot 006)$, but the preferred temperature did not differ significantly within each group according to the substance drunk. For each of coffee and tea, subjects in the disease group chose to drink at higher temperatures than the control group ( $p<0.001$ for each substance). The addition of milk and/or sugar did not influence the results.

\section{Discussion}

Despite extensive research into possible aetiologies of peptic ulceration the overall picture remains incomplete. The role of the temperature of the diet as a potential aetiological or exacerbating factor has arisen intermittently since William Beaumont ${ }^{15}$ described temperature change in the stomach of a patient with gastric fistula and finally laid to rest the Hippocratic and Galenic concepts of a 'gastric oven'. $\mathrm{He}$ noted no change in temperature between the resting stomach and the stomach after meals. Since then various authors have suggested that the temperature of the diet had a causative role in peptic ulceration, ${ }^{131317}$ oesophagitis or oesophageal

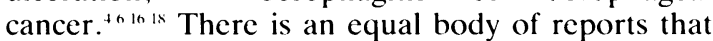
temperature is not of importance in these conditions."

Man is unique in choosing to eat and drink at temperatures far removed from normal body temper- 
ature. Hunt ${ }^{12}$ found that in a large group of healthy, young medical students the mean temperature of choice for a hot drink was $60.02^{\circ} \mathrm{C}$ for men and $61.29^{\circ} \mathrm{C}$ for women (range $46^{\circ}-76^{\circ} \mathrm{C}$ ). Davis and Ivy, ${ }^{1+}$ in a slightly different method but in a similar group of healthy volunteers, found the mean oral temperature tolerance to be $57 \cdot 8^{\circ} \mathrm{C}$, range $51^{\circ}-68^{\circ} \mathrm{C}$. That people should choose to drink at such high temperatures is remarkable when compared with a hot bath which is comfortable at $43^{\circ} \mathrm{C}$ and barely tolerable at $44^{\circ} \mathrm{C}$.

In the present study the two groups were similar with respect to age and sex, but as expected there were more smokers in the disease group than in the controls. As a group, patients with peptic diseases preferred hotter drinks than did asymptomatic controls, and this was true for disease of the oesophagus, stomach and duodenum and for patients with mixed disease. The median temperature of choice for hot drinks was greatest in patients with oesophageal disease, followed by those with gastric disease and then those with duodenal disease, patients with mixed disease lying in the middle of the range. Smoking did not influence these results, as smokers and non-smokers within the disease group preferred their drinks hotter than the asymptomatic controls. Non-smokers in the disease groups chose to drink at higher temperatures than the smokers in that group whereas there was no difference between nonsmokers and smokers when disease status was ignored.

As a group, our patients did not experience discomfort when the temperature of their drink was 'just right'. Some had altered their drinking habit since developing oesophagitis and the temperature at which they habitually drank did cause pain, and they therefore now drank it cooler. This cooler, more comfortable temperature has not been excluded from the data which may thus skew the results downwards. Had they continued to drink at their accustomed temperature, the differences between control and disease groups would have been greater. As the preferred temperature decreased with age in the control group, the greater spread of preferred temperature within the disease group may reflect a loss of sensory protection in the disease group becoming more apparent with advancing age. There is no apparent reason, however, why this should affect any one section of the population and not the other. An alternative explanation is that disease patients in the older age group are simply those younger patients from the control group with a relatively high preferred temperature, later developing overt peptic disease. This could only be proven by a longterm prospective cohort study.

The lack of significant difference in preferred temperature between the two sexes would negate
Logan Turner's hypothesis that women drinking hot tea explains the reversal of normal sex incidence that he found with post cricoid cancer.

That high temperature can damage tissues is evident from our knowledge of burns to the skin. The tertiary structure of proteins is destroyed at $43^{\circ} \mathrm{C}$ and the lethal temperature for leukocytes, cell cultures and transplants is $47^{\circ} \mathrm{C} .{ }^{11}$ What is less certain is the minimum temperature that can be tolerated by any tissue and by the oesophagogastric mucosa in particular. Losch" caused extensive damage to gastric mucosa with hot water at $60-80^{\circ}$ Celsius and Hirai ${ }^{2}$ induced gastritis in dogs when they were fed food at $46^{\circ}$ Celsius. Edwards and Edwards ${ }^{13}$ found that the temperature of choice for drinks increased with severity of histological grade of gastritis in a series of patients who had undergone gastric biopsy, from normal (mean temperature $53 \cdot 6^{\circ} \mathrm{C}$ ), to atrophic gastritis (mean temperature $57 \cdot 28^{\circ} \mathrm{C}$ ).

More recent and direct evidence of hyperthermic cellular damage stems from research in the 1960s and 70 s into the use of hyperthermia, both local and whole body, in the treatment of solid tumours. Although the majority of these studies were concerned with malignant tissue, their control experiments show that there was a linear decrease in cell survival with increasing exposure of cultured cell populations to temperatures of between $41^{\circ}-43^{\circ} \mathrm{C}$. Some workers ${ }^{2 n}{ }^{27}$ have suggested that the differential effects of hyperthermia on malignant cells may be related to a relatively inefficient heat sump effect of tumour vascularity compared with normal vascularity such that the temperature within the tumour reaches a higher level than in the surrounding well vascularised normal tissue. This may have some relevance to peptic disorders where a relatively inefficient gastric heat sump may predispose to thermal injury in patients who habitually take particularly hot food or drink. These factors can only be resolved by accurate intraluminal recordings of the temperature profile in the upper gastrointestinal tract of man..$^{2 x}$

The first line of defence against ingested food or drink in the stomach is gastric mucus but the effects of temperature on mucus are not well documented. Snary ${ }^{24}$ showed that viscosity of mucus increased with temperature for any finite concentration but there was no large change in the intrinsic viscosity of mucoprotein between $20^{\circ}$ and $45^{\circ} \mathrm{C}$. Meyer, ${ }^{31}$ however, showed irreversible thermal degradation of mucus incubated over a wide range of temperature up to $60^{\circ} \mathrm{C}$. Both these studies were using temperature to elucidate the structure of mucus and did not comment on its clinical implications relating to temperature of diet.

We conclude that patients with peptic diseases of 
the upper gastrointestinal tract are drinking hot drinks at higher temperatures than their asymptomatic counterparts. They are doing so at temperatures which would normally be injurious to skin and presumably to mucosa. If these high temperatures are transmitted down the lumen of the upper gastrointestinal tract they may be causally related to peptic ulceration in some patients and could alter the advice we should offer to these patients.

A part of this work has been published in abstract form (Br J Surg 1987; 74: 1160).

\section{References}

1 Lauder Brunton T. Disorders of digestion. London: MacMillan, 1886: 65.

2 Ewald CA. Lectures on diseases of the digestive organs. Volume 1 Lectures on digestion. (Translation by Saundby R.) London: The New Sydenham Society, 1891.

3 Heiser A. Med Klin 1922; 18: 1025.

4 Turner AL. Malignant discase of oesophagus with specific reference to carcinoma of the upper end: a clinical study based upon an analysis of 68 cases of tumour. J Laryng Rhin Otol 1913; 28: 281-306.

5 Turner AL. Carcinoma of the post cricoid region and upper end of oesophagus. J Laryng Rhin Otol 1920; 35:34.

6 Watson WL, Goodner JT. Carcinoma of the oesophagus. Am J Surg 1957; 93: 259.

7 Herbert WE, Bruske JS. Actiology of cancer of the stomach: a comparison of the diet and dental conditions of the English and Dutch with special reference to gastric irritants. Guys Hosp Rep 1936; 86: 301-8.

8 Mann WN, Sundberg S, Herbert WE. Cancer in the stomach in London, in Stockholm and in Amsterdam. Guys Hosp Rep 1939; 89: 274-84.

9 Mosbech J, Videbaek A. On the aetiology of oesophageal carcinoma. $J$ Natl Cancer Inst 1955; 15: 1665-73.

10 Dunham LJ, Brunschwig A. A review of dictary and related habits in patients with malignant gastric neoplasms. Gastroenterology 1946; 6: 286-93.

11 Mosbech J, Videbaek A. The aetiology of gastric carcinoma clucidated by a study of 302 pedigrees. Acta Med Scand 1954; 149: 137-59.

12 Hunt JN. The temperature of choice for hot drinks: a comparison of men and women. Guys Hosp Rep 1947; 96: 6()-3.
13 Edwards FC, Edwards JH. Tea drinking and gastritis. Lancet 1956; ii: 543-5.

14 Davis RE, Ivy AC. Thermal irritation in gastric disease. Cancer 1949; 2: 138-43.

15 Beaumont W. Experiments and observations on the gastric juice and the physiology of digestion. Plattsburg: FP Allen, 1833: 108.

16 Bockus HL. Gastroenterology. Philadelphia: WB Saunders, 1963.

17 Van Valzah WW, Nisbet JD. The diseases of the stomach. Philadelphia: WB Saunders, 1898.

18 Vassallo A, Correa P, de Stefani E, et al. Esophageal cancer in Uruguay: a case control study. $J$ Natl Cancer Inst 1985; 75: 1005-9.

19 Leach EH, Peters RA, Rossiter RJ. Experimental thermal burns, especially moderate temperature burns. QJ Exp Physiol 1943; 32: 67-86.

20 Losch F. Quoted in Bockus HL. Gastroenterology. Philadelphia: WB Saunders, 1963: 375.

21 Hirai Y. Experimental studies on effect of hot food on the mucous membrane of stomach. Acta Medica Jgaku Kenkyua 1954; 24: 163.

22 Hahn GM. Metabolic aspects of the role of hyperthermia in mammalian cell inactivation and their possible relevance to cancer treatment. Cancer Res 1974; 34: $3117-23$.

23 Hahn GM. Potential for therapy of drugs and hyperthermia. Cancer Res 1979; 39: 2264-8.

24 Kase K. Hahn GM. Differential heat response of normal and transformed human cells in tissue culture. Nature 1975; 255: 228-30.

25 Harisiadis L, Sung Duk II, Hall EJ. Thermal tolerance and repair of thermal damage by cultured cells. Radio$\log y$ 1977; 123: 505-9.

26 LeVeen HH, Wapnick S, Piccone V, Falk G, Ahmed N. JAMA 1976; 235: 2198-200.

27 Song CW. Effect of hyperthermia on vascular functions of normal tissues and experimental tumours. J Natl Cancer Inst 1978; 60: 711-3.

28 Pearson RC, McCloy RF, Cutler WC, Levitt JR, Richards B, Vickery JC. Multichannel digital recording of intraluminal temperature in the upper gastrointestinal tract of man: techniques and analyses. Clin Phys Physiol Meas 1988; 9: 243-8.

29 Snary D, Allen A. Pain RH. The effect of temperature on gel formation in pig gastric mucus. Eur $\mathrm{J}$ Biochem 1973; 36: 72-5.

30 Meyer FA. Mucus structure: relation to biological transport function. Biorheology 1976; 13: 49-58. 